\title{
Cómo ser mejor maestro. El método ELI
}

Autor: Ramón Ferreiro Gravié

Editorial: Trillas

Año de publicación: 2012 (reimp. 2014)

Número de páginas: 296

ISBN: 978-607-17-1043-7

Ramón Ferreiro, profesor de la Fischler School of Education and Human Services de Nova Southeastern University, presenta en esta ocasión una obra que combina con lucidez el rigor académico con una visión transformadora de la práctica docente. Con un título sugerente, que invita al lector a encarar animado su lectura, la obra "Cómo ser mejor maestro: el método ELI" viene a sintetizar los esfuerzos del autor por ofrecer claves de sentido y significado a los docentes en formación inicial y en ejercicio en la búsqueda de un método flexible y adaptado a los modos de enseñar y aprender del momento.

La obra es la tercera edición, actualizada y ampliada, del libro "Estrategias didácticas del aprendizaje cooperativo. El constructivismo social: una nueva forma de enseñar y aprender". Su estructura se ordena en doce capítulos que abordan, en una primera parte inicial, los paradigmas psicopedagógicos el enfoque del constructivismo sociocultural y el aprendizaje cooperativo. Precisamente, estos tres primeros capítulos son la base fundamental sobre la que el autor desarrolla su propuesta singular, el método ELI.

El método ELI es el proceso y el resultado de una investigación internacional longitudinal, llevada a cabo entre 1977 y 2008 a través del seguimiento de cohortes de estudiantes en su recorrido por el sistema educativo a partir de un enfoque de investigación eminentemente cualitativo. El método está avalado por diferentes consejos científicos de instituciones de educación superior desde la década de 1980 hasta el hasta el reconocimiento más reciente, en 2008, por parte del Scientific Board de Nova Southeastern University.

Su concepción y sentido, presentados en el capítulo cuarto, exige al docente mediar entre el alumno y el contenido de aprendizaje a la vez que profundiza en las concepciones de los discentes sobre el aprendizaje. Se hace necesario acudir a estrategias centradas en el estudiante que se implementan desde una planificación sistemática y flexible de la docencia. A su vez, tal y como el profesor Ferreiro constata, el método ELI permite desarrollar competencias profesionales en los docentes a la vez que se mejoran los aprendizajes esperados por los estudiantes.

La obra continua en los capítulos siguientes con la propuesta de estrategias didácticas que desarrollan los siete momentos claves identificados por el autor para dar sentido operativo a su método. Serían, en definitiva, las siete funciones didácticas imprescindibles para aumentar las posibilidades de aprendizaje de los estudiantes. De un modo sintético, estos momentos refieren a la creación de ambientes favorables para aprender y de activación de los procesos neuropsicológicos que hacen posible el 
aprendizaje (momento A), el procesamiento de la información (momento PI), la recapitulación de lo que se va aprendiendo (momento R), la evaluación de los aprendizajes (momento E), la interdependencia social positiva (momento I), la reflexión sobre procesos y resultados de la actividad de aprendizaje (momento M) así como la orientación de la atención (momento O).

Estos momentos forman parte de un sistema integrado e interrelacionado que permiten orientar la actuación docente. No han de entenderse como pasos secuenciados o actuaciones pautadas de un modo rígido y estándar, más bien han de concebirse como elementos necesarios a contemplar en el proceso de enseñanza. Son funciones didácticas que implican su necesaria consideración y planificación, si se quiere desarrollar una práctica docente sostenible y pertinente al objeto de enseñar a aprender y estimular, a la vez, el aprendizaje personalizado de los estudiantes, apoyándose en la reflexión del docente tras la enseñanza al objeto de ponderar los logros evidentes y avances relevantes de los aprendizajes de los estudiantes.

Sin duda, es un método de interés susceptible de ser propuesto a maestros en formación. También a profesores y educadores en ejercicio preocupados por su formación, por la potencialidad del método para estimular procesos innovadores en las instituciones educativas. Una propuesta avalada y contrastada por distintas instituciones y altamente difundida en diversos contextos por el Dr. Ferreiro, quien además ha recibido recientemente el nombramiento Honoris Causa por la Universidad de Santander (México). Todo ello, obra y autor, no hace más que animarnos a recomendar un libro que propone con sencillez y rigor un método para ser mejor maestro. 